\title{
Sensitivity Improvement of Ammonia Gas Sensor Based on Poly(3,4-ethylenedioxythiophene):Poly(styrenesulfonate) by Employing Doping of Bromocresol Green
}

\author{
La Aba, ${ }^{1,2}$ Yusril Yusuf, ${ }^{1}$ Mitrayana, ${ }^{1}$ Dwi Siswanta, ${ }^{3}$ Junaidi, ${ }^{4}$ and Kuwat Triyana ${ }^{1}$ \\ ${ }^{1}$ Physics Department, Gadjah Mada University, Sekip Utara BLS.21, Yogyakarta 55281, Indonesia \\ ${ }^{2}$ Physics Department, Haluoleo University, Jl. HEA Mokodompit, Kampus Hijau Bumi Tridharma Anduonohu, \\ Kendari 93232, Indonesia \\ ${ }^{3}$ Chemistry Department, Gadjah Mada University, Sekip Utara BLS.21, Yogyakarta 55281, Indonesia \\ ${ }^{4}$ Physics Department, Lampung University, Jl. Prof. Dr. Sumantri Brojonegoro No. 1, Bandar Lampung 35145, Indonesia
}

Correspondence should be addressed to Kuwat Triyana; triyana@ugm.ac.id

Received 31 July 2013; Revised 15 November 2013; Accepted 1 December 2013; Published 22 January 2014

Academic Editor: Yoke Khin Yap

Copyright $\odot 2014$ La Aba et al. This is an open access article distributed under the Creative Commons Attribution License, which permits unrestricted use, distribution, and reproduction in any medium, provided the original work is properly cited.

The aim of this research is to improve the sensitivity of ammonia gas sensor (hereafter referred to as sensor) based on poly(3,4ethylenedioxythiophene):poly(styrenesulfonate) (PEDOT:PSS) by employing the doping dye of bromocresol green (BCG). The doping process was carried out by mixing the BCG and the PEDOT:PSS in a solution with an optimum ratio of 1:1 in volume. The sensor was fabricated by using spin-coating technique followed by annealing process. For comparison, the BCG thin film and the PEDOT:PSS thin film were also deposited with the same method on glass substrates. For optical characterization, a red-light laser diode with a $650 \mathrm{~nm}$ wavelength was used as light source. Under illumination with the laser diode, the bare glass substrate and BCG film showed no absorption. The sensor exhibited linear response to ammonia gas for the range of $200 \mathrm{ppm}$ to $800 \mathrm{ppm}$. It increased the sensitivity of sensor based on PEDOT:PSS with BCG doping being about twofold higher compared to that of without BCG doping. Furthermore, the response time and the recovery time of the sensor were found very fast. It suggests that the optical sensor based on BCG-doped PEDOT:PSS is promising for application as ammonia gas sensor.

\section{Introduction}

Ammonia gas has pungent odour and is colourless and lighter than air. It is known as a toxic compound that can be harmful to the human health if presents at high concentration [1]. In this regards, the device to detect ammonia gas is extremely necessary. Recently, there are many reports related to the development of gas sensors based on polymers because of advantages such as easy fabrication, low power consumption, room temperature operation, and being independent from environmental interference [2]. A hybrid material for ammonia gas sensor has been developed by electrochemical incorporation of phthalocyanine in conducting polypyrrole [3-5]. The polypyrrole films have been electrochemically deposited on microelectrodes arrays by using silicon microtechnologies. Its sensing properties to ammonia gas were investigated by considering electrodeposition parameters [6,7]. Beside polypyrrole, another polymer for ammonia gas sensor is polyaniline $[8,9]$. The electrical impedance spectroscopy and amperometry of polyaniline have also been modified for ammonia gas sensor [10]. As gas sensor material, the conducting polymer interacts with gas molecules resulting in a change bipolaron density inside the band gap [2]. It is well known that the bipolaron excitations generally fall in the visible range, so that both electrical and optical properties of the conducting polymer change by varying the concentration of gas.

Another conducting polymer, PEDOT:PSS, also exhibits promising potential for ammonia gas sensor. The work function of PEDOT:PSS is about $5.0 \mathrm{eV}$. For another application, PEDOT:PSS is usually used to prevent an organic solar cell from short circuit condition [11]. Much efforts have been 


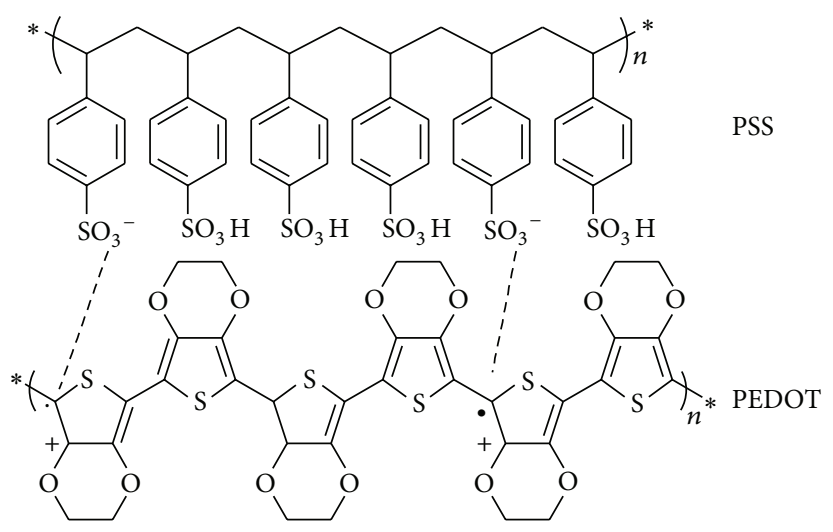

(a)<smiles>CC1=C(Br)C(=O)C(Br)=CC1=C(c1ccccc1[S+](=O)[O-])c1cc(Br)c(O)c(Br)c1C</smiles>

Bromocresol green

(b)

FIgURE 1: Molecular structures of (a) PEDOT:PSS and (b) bromocresol green (BCG).

devoted to improve the performance of ammonia gas sensor based on PEDOT:PSS. In order to increase the selectivity of the sensor to ammonia gas, the imprinting method has been employed [12]. Beside electrical properties, the investigation on optical properties of ammonia gas sensor has also been carried out with dye doping [13] and without doping [2]. Investigation on conductive inverse opal films of PEDOT as ammonia gas sensor was also performed by depositing into the void space of silica colloidal crystal temples and followed with silica-etching. From this method, more rapid response has been obtained through optical measurement rather than electrical measurement [14]. Since the PEDOT:PSS is dissolved in water, it is influenced by humidity around the sensor [15].

In this study, we used doping of BCG to PEDOT:PSS for increasing the sensitivity of sensor to ammonia gas because BCG is basically dye for a pH indicator. The BCG can be yellow in acidic condition and blue in basic condition [16]. For this purpose, BCG-doped PEDOT:PSS was deposited on glass substrate by using spin-coating technique. The sensing system is very cheap because it was illuminated with a red laser diode and the light transmitted through the sensing layer was detected by $\mathrm{p}-\mathrm{i}-\mathrm{n}$ silicon photodiode.

\section{Experimental Method}

2.1. Material. The conducting polymer used in this study was PEDOT:PSS purchased from H.C. Starck of Clevios PH500 without further treatment, while the dye used as doping of PEDOT:PSS was BCG. The molecular structures of both materials are as shown in Figure 1.

2.2. Sample Preparation and Gas Sensor Fabrication. Firstly, the BCG in aqueous solution was prepared with a concentration of $5 \mathrm{mM}$. Then the solution was mixed with PEDOT:PSS with a ratio of $1: 1$ in volume. Secondly, a mixture of BCG:PEDOT:PSS was stirred with a magnetically driven paddle for $1 \mathrm{~h}$. Then, the BCG-PEDOT:PSS film was deposited on a cleaned glass substrate by using spin-coating technique at a speed of 1,000 rpm for 20 seconds followed by annealing at $100^{\circ} \mathrm{C}$ for 30 minutes to remove the solvent. Other ratios will be reported elsewhere.

2.3. Optical Characterization. The block diagram of the optical measurement system for ammonia gas sensor used in this study is shown in Figure 2. The used light source was a red laser diode $(\lambda=650 \mathrm{~nm})$. The size of gas chamber is about $12 \mathrm{~cm}^{3}$. The $\mathrm{p}-\mathrm{i}-\mathrm{n}$ silicon photodiode (type BPV10) was connected in series with a resistor of $20 \mathrm{k} \Omega$ and mounted in the opposite direction to the red laser diode. This optical measurement system was equipped with an automatic data acquisition system. Prior to applying the measurement system, the developed data acquisition system was calibrated by using the National Instrument of type BNC-2110. 


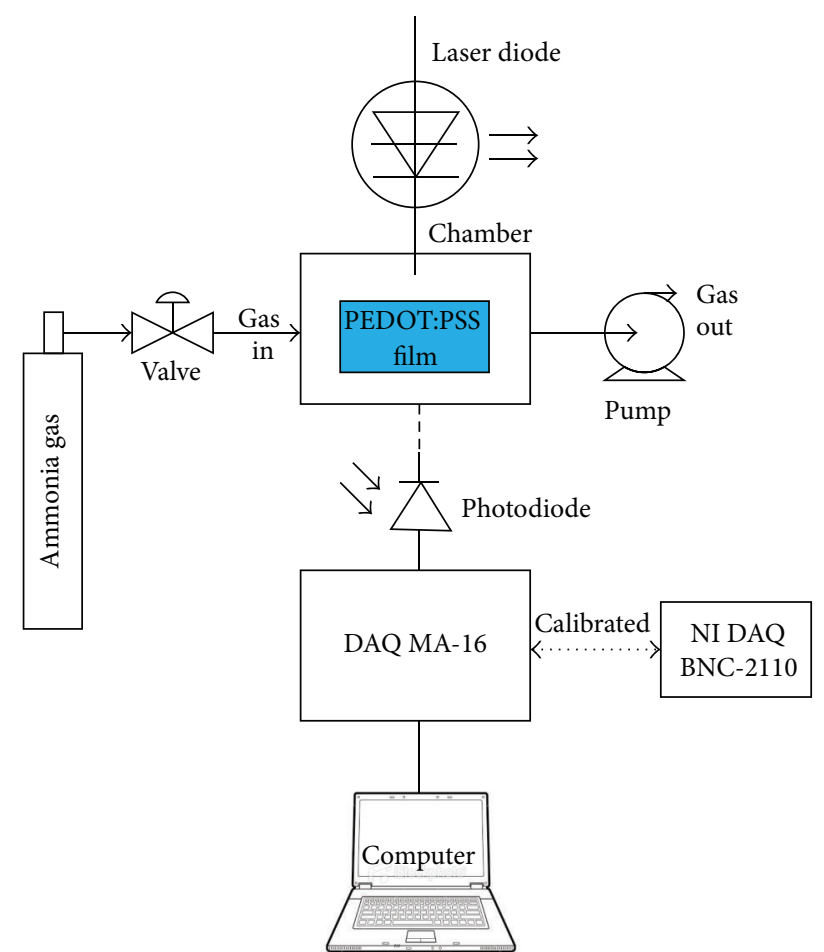

FIGURE 2: Experimental setup of optical measurement system of ammonia gas sensor.

After installing the sensor into the gas chamber, the optical measurement of the sensor was carried out by injecting a certain concentration of ammonia gas into the chamber. An aerator pump was used to remove the ammonia gas from the chamber. All processes in this experiment were carried out at ambient temperature. The sensor response was recorded as voltages, that is, $V_{g}$ (under exposing ammonia gas) and $V_{a}$ (under exposing air ambient).

\section{Results and Discussion}

3.1. Optical Response. To investigate the effect of BCG doping on the sensitivity of sensor to ammonia gas, the response of four kinds of device were measured, namely, bare glass, glass coated with BCG, glass coated with PEDOT:PSS, and glass coated with BCG-PEDOT:PSS. In this study, the sensor response is defined as normalized sensor output voltage, that is, $\left(V_{a}-V_{g}\right) / V_{a}$.

The color of PEDOT:PSS changes when there is a change in electrochemical potential. The color of PEDOT:PSS thin film is light blue when in the undoped state and it turned into a dark blue when in the doped state [16]. The color of PEDOT:PSS also changes from light blue to dark blue when absorbing gas ammonia. It is because ammonia gas is an electron-donor. Discoloration of the PEDOT:PSS may result in the changes in the transmittance of light passing through the thin film. In this case, the light transmittance is reduced after passing through the film when it is exposed to ammonia gas. By a photodiode, the transmitted light intensity is then converted into electrical voltage.

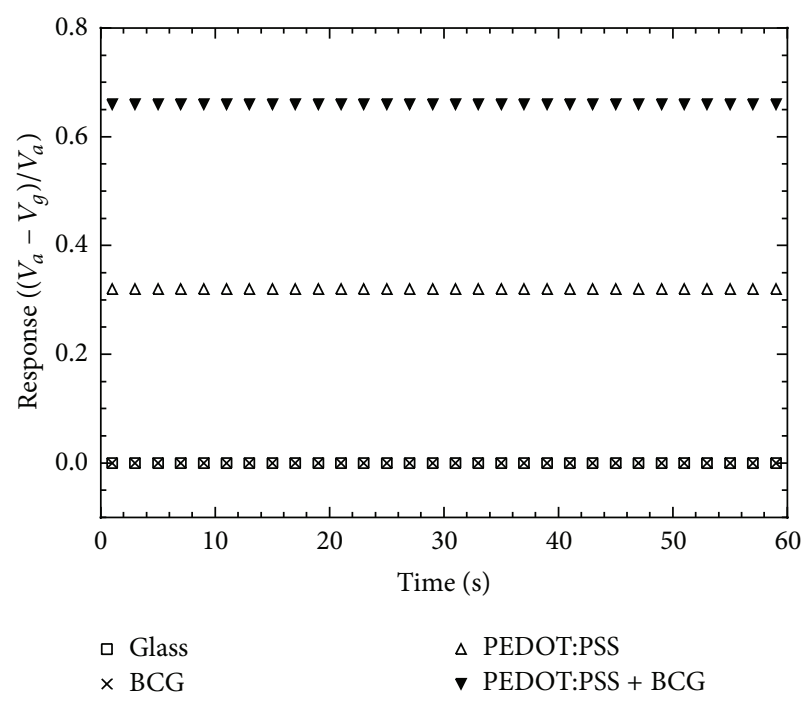

FIGURE 3: Response profile of ammonia sensor based BCGPEDOT:PSS-based sensor for different concentrations of ammonia gas.

Figure 3 shows the response profile of devices to ammonia gas at the same concentration, where the device based on only BCG thin film on glass substrate did not respond to ammonia gas. On the other hand, the sensitivity of sensor to ammonia gas based on PEDOT:PSS with BCG doping was about twofold higher compared to that of without BCG doping. When the PEDOT:PSS thin film adsorbs ammonia gas, the output voltage is reduced compared to that of ambient air. This phenomenon can be explained by optically sensing mechanism. At least there are two mechanisms for optically detecting ammonia gas. The first mechanism is due to the color changes when ammonia gas reacts with PEDOT:PSS thin film. The second mechanism is due to the changes in optical absorption [12].

The BCG is usually used for acid-base indicator; the color of BCG is yellow in acidic condition. The color of BCG turns to blue in base condition $[16,17]$. The addition of the yellow solution of BCG to the PEDOT:PSS with blue color results in a color mixing between yellow and blue colors to be yellowish blue.

Separately, the BCG does not adsorb ammonia gas (see Figure 3), so that its color does not change to the ammonia gas. The PEDOT:PSS, on the other hand, responds to ammonia gas by changing its color from light to dark blue because the ammonia gas is base. By combining PEDOT:PSS and BCG, the BCG plays a role by increasing the color of PEDOT:PSS to be more dark blue. Furthermore, this change of color results in decreasing the transmittance intensity of light after passing through the film. As an optical measurement system, all changes in transmitted light intensity are detected by photodiode.

3.2. Sensitivity. Sensitivity of a sensor is defined as the change in output of the sensor per unit change in the parameter 


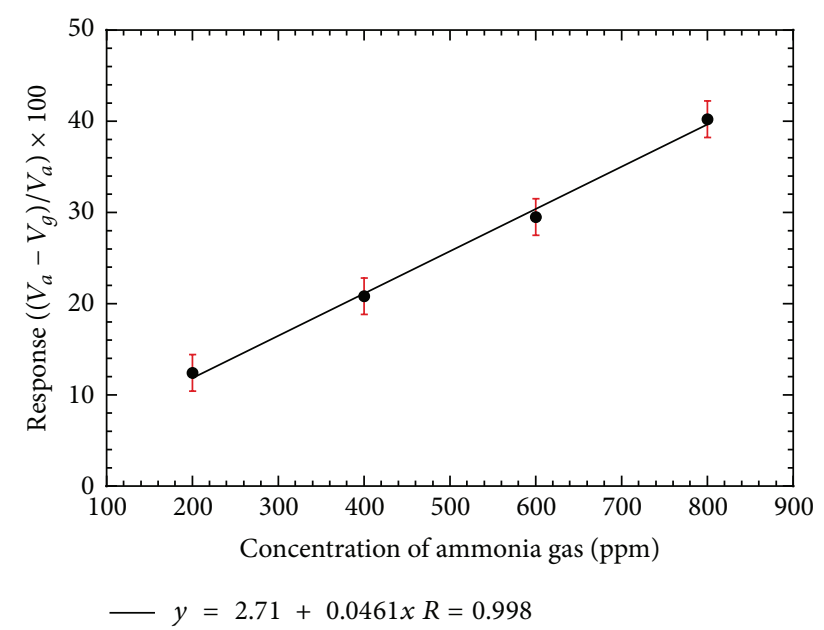

FIGURE 4: Linear correlation between response and ammonia gas concentration of gas sensor based on BCG-PEDOT:PSS.

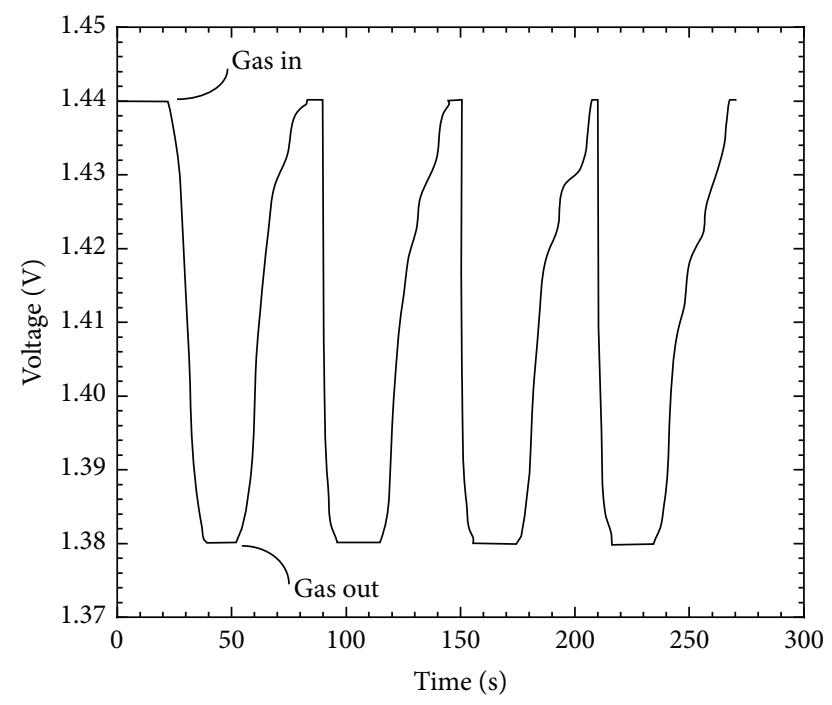

FIGURE 5: The on/off response profile of sensor based on BCGPEDOT:PSS to ammonia gas.

being measured. The response of sensor based on BCGPEDOT:PSS thin film to ammonia gas with different concentrations is depicted in Figure 4. It shows that the response of sensor increases linearly to the concentration of ammonia gas. From this result, it can be calculated to obtain the sensitivity of the sensor to be about $0.05 \% / \mathrm{ppm}$. This value may be still lower compared to the sensitivity of commercial sensors, but it is about 2-fold more than sensitivity of the ammonia gas sensor based on imprinted PEDOT:PSS [10]. Furthermore, this sensitivity is much higher for about 24 -fold compared to that of ammonia gas sensor based on polyaniline by using optical measurement [12].

The on/off response profile of the sensor based on BCG-PEDOT:PSS for four cycles measurement is shown in Figure 5. The output voltage of sensor decreases dramatically when it is exposed to ammonia gas (gas in). It indicates that the response of the sensor is reversible for on/off condition to the exiting of ammonia gas. The response time of the sensor is found to be about 1 second, while the recovery time is much longer for about 15 seconds. This fast optical response is one of merits compared to the conventional measurement based on electrical property $[13,14]$. We can also see in Figure 5 that the response times for the entire cycles are relatively similar, whereas the recovery time increases with the increasing of measurement cycles.

\section{Conclusion}

Optically, the response of sensor is represented by the change in intensity of transmitted light after passing the sensor layer. Separately, the BCG has no response to ammonia gas; the BCG only contributes to the increasing sensitivity of sensor after being mixed with PEDOT:PSS. It is proven that the sensitivity of ammonia gas sensor based on PEDOT:PSS thin film has been improved by employing doping dye of BCG. The response of sensor increases linearly by increasing the concentration of ammonia gas with sensitivity of the sensor being about $0.05 \%$ per ppm. Compared to the sensor without doping, the sensitivity of ammonia gas sensor after doping is almost twofold higher.

\section{Conflict of Interests}

The authors declare that there is no conflict of interests regarding the publication of this paper.

\section{Acknowledgments}

The work was partially supported by "Hibah Riset Unggulan UGM" under Research Grant No. LPPM-UGM/1027/2009, MAK. 2311.0154.521219.

\section{References}

[1] T. Hibbard, K. Crowley, and A. J. Killard, "Direct measurement of ammonia in simulated human breath using an inkjet-printed polyaniline nanoparticle sensor," Analytica Chimica Acta, vol. 779, pp. 6-63, 2013.

[2] Y.-S. Lee, B.-S. Joo, N.-J. Choi, J.-O. Lim, J.-S. Huh, and D.-D. Lee, "Visible optical sensing of ammonia based on polyaniline film," Sensors and Actuators B, vol. 93, no. 1-3, pp. 148-152, 2003.

[3] J. Janata and M. Josowicz, "Conducting polymers in electronic chemical sensors," Nature Materials, vol. 2, no. 1, pp. 19-24, 2003.

[4] H. Bai and G. Shi, "Gas sensors based on conducting polymers," Sensors, vol. 7, no. 3, pp. 267-307, 2007.

[5] T. Patois, J.-B. Sanchez, F. Berger et al., "Elaboration of ammonia gas sensors based on electrodeposited polypyrrole-Cobalt phthalocyanine hybrid films," Talanta, vol. 17, pp. 45-54, 2013.

[6] S. Carquigny, J.-B. Sanchez, F. Berger, B. Lakard, and F. Lallemand, "Ammonia gas sensor based on electrosynthesized polypyrrole films," Talanta, vol. 78, no. 1, pp. 199-206, 2009.

[7] T. Patois, J.-B. Sanchez, F. Berger, J.-Y. Rauch, P. Fievet, and B. Lakard, "Ammonia gas sensors based on polypyrrole films: 
influence of electrodeposition parameters," Sensors and Actuators B, vol. 171-172, pp. 431-439, 2012.

[8] H. Kebiche, D. Debarnot, A. Merzouki, F. Poncin-Epaillard, and N. Haddaoui, "Relationship between ammonia sensing properties of polyaniline nanostructures and their deposition and synthesis methods," Analytica Chimica Acta, vol. 737, pp. 64-71, 2012.

[9] D.-M. Xu, M.-Y. Guan, Q. -Hong Xu, and Y. Guo, "Multilayer films of layered double hydroxide/polyaniline and their ammonia sensing behavior," Journal of Hazardous Materials, vol. 262, pp. 64-70, 2013.

[10] S. P. Basak, B. Kanjilal, P. Sarkar, and A. P. F. Turner, "Application of electrical impedance spectroscopy and amperometry in polyaniline modified ammonia gas sensor," Synthetic Metals, vol. 175, pp. 127-133, 2013.

[11] K. Triyana, T. Yasuda, K. Fujita, and T. Tsutsui, "Improvement of heterojunction donor/acceptor organic photovoltaic devices by employing additional active layer," Japanese Journal of Applied Physics, vol. 44, no. 4 A, pp. 1974-1977, 2005.

[12] L. Aba, Y. Yusuf, Mitrayana, and K. Triyana, "Selectivity improvement of gas sensor based on poly(3,4-ethyl-enedioxythiophene): poly(styrenesulfonate) thin film by using imprinting method," Journal of Modern Physics, vol. 3, no. 7, pp. 529-533, 2012.

[13] F. Tavoli and N. Alizadeh, "Optical ammonia gas sensor based on nanostructure dye-doped polypyrrole," Sensors and Actuators B, vol. 176, pp. 761-767, 2013.

[14] Q. Zhong, H. Xu, H. Ding et al., "Preparation of conducting polymer inverse opals and its application as ammonia sensor," Colloids and Surfaces A, vol. 433, pp. 59-63, 2013.

[15] P. Pacher, A. Lex, S. Eder et al., "A novel concept for humidity compensated sub-ppm ammonia detection," Sensors and Actuators B, vol. 145, no. 1, pp. 181-184, 2010.

[16] D. Diamond, K. T. Lau, S. Brady, and J. Cleary, "Integration of analytical measurements and wireless communicationscurrent issues and future strategies," Talanta, vol. 75, no. 3, pp. 606-612, 2008.

[17] A. El-Didamony and S. Hafeez, "Spectrophotometric determination of thioridazine hydrochloride in tablets and biological fluids by ion-pair and oxidation reactions," Spectroscopy: An International Journal, vol. 27, no. 3, pp. 129-141, 2012. 

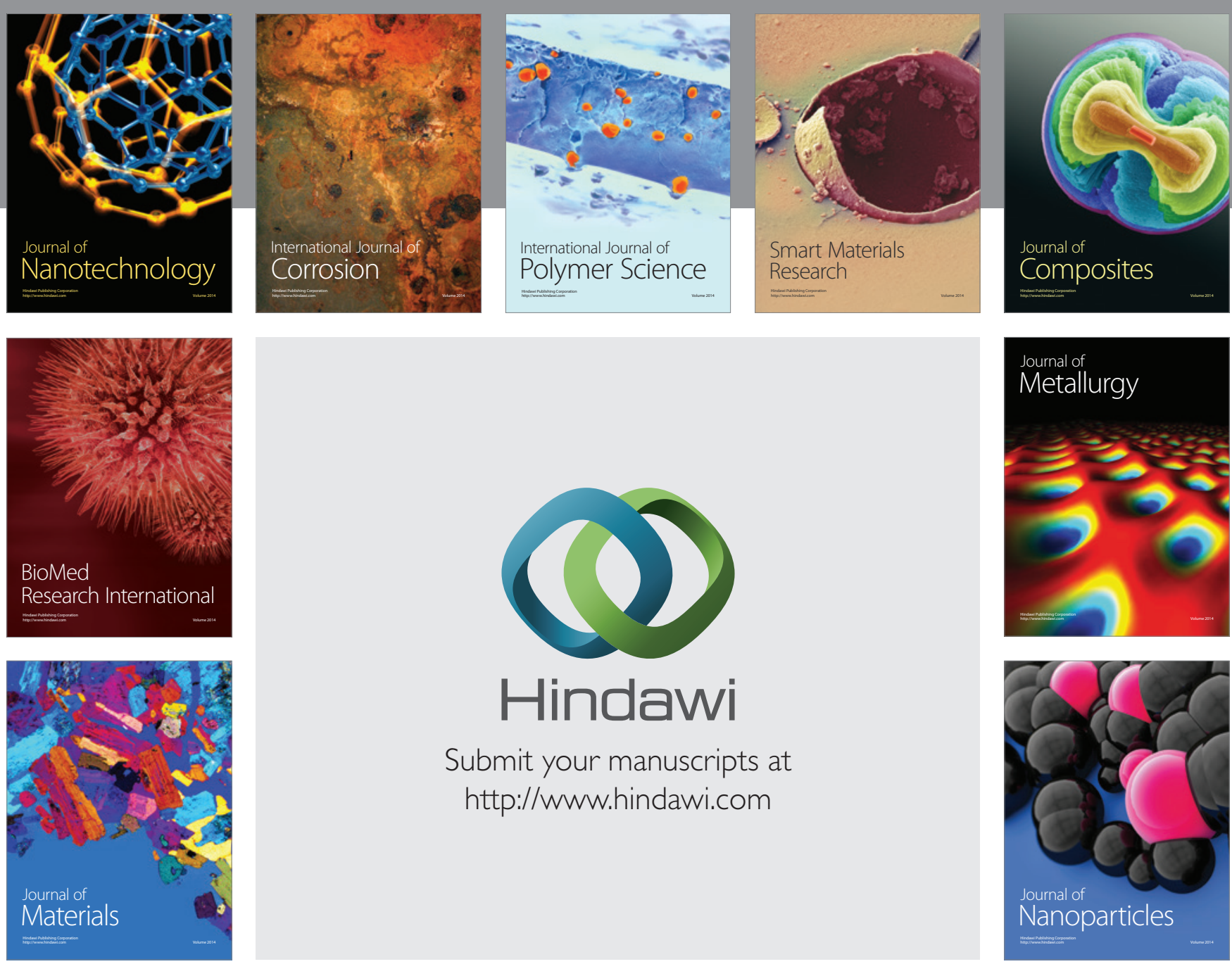

Submit your manuscripts at http://www.hindawi.com
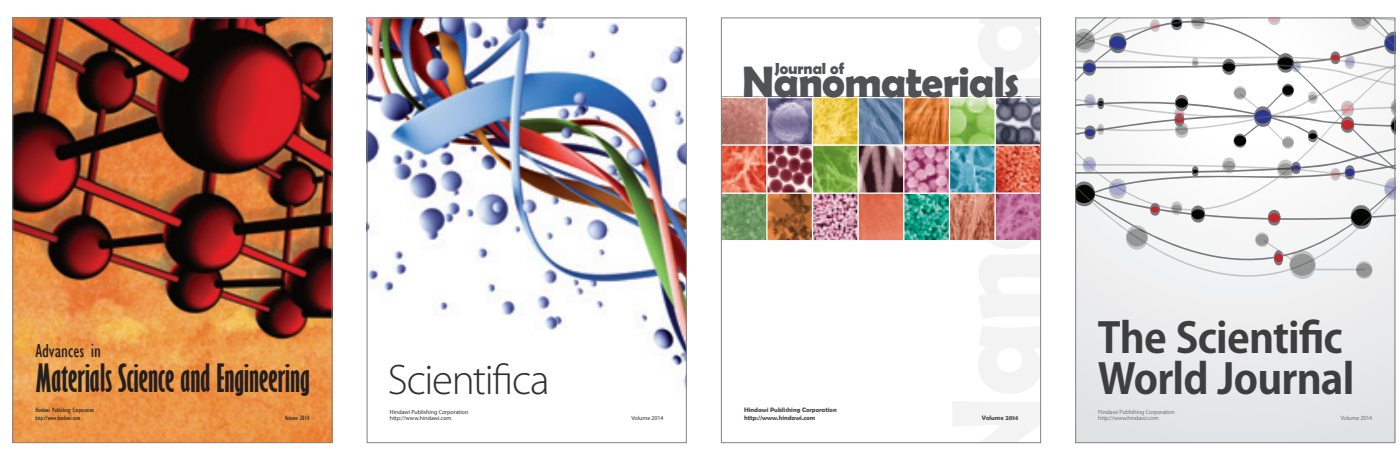

\section{The Scientific World Journal}
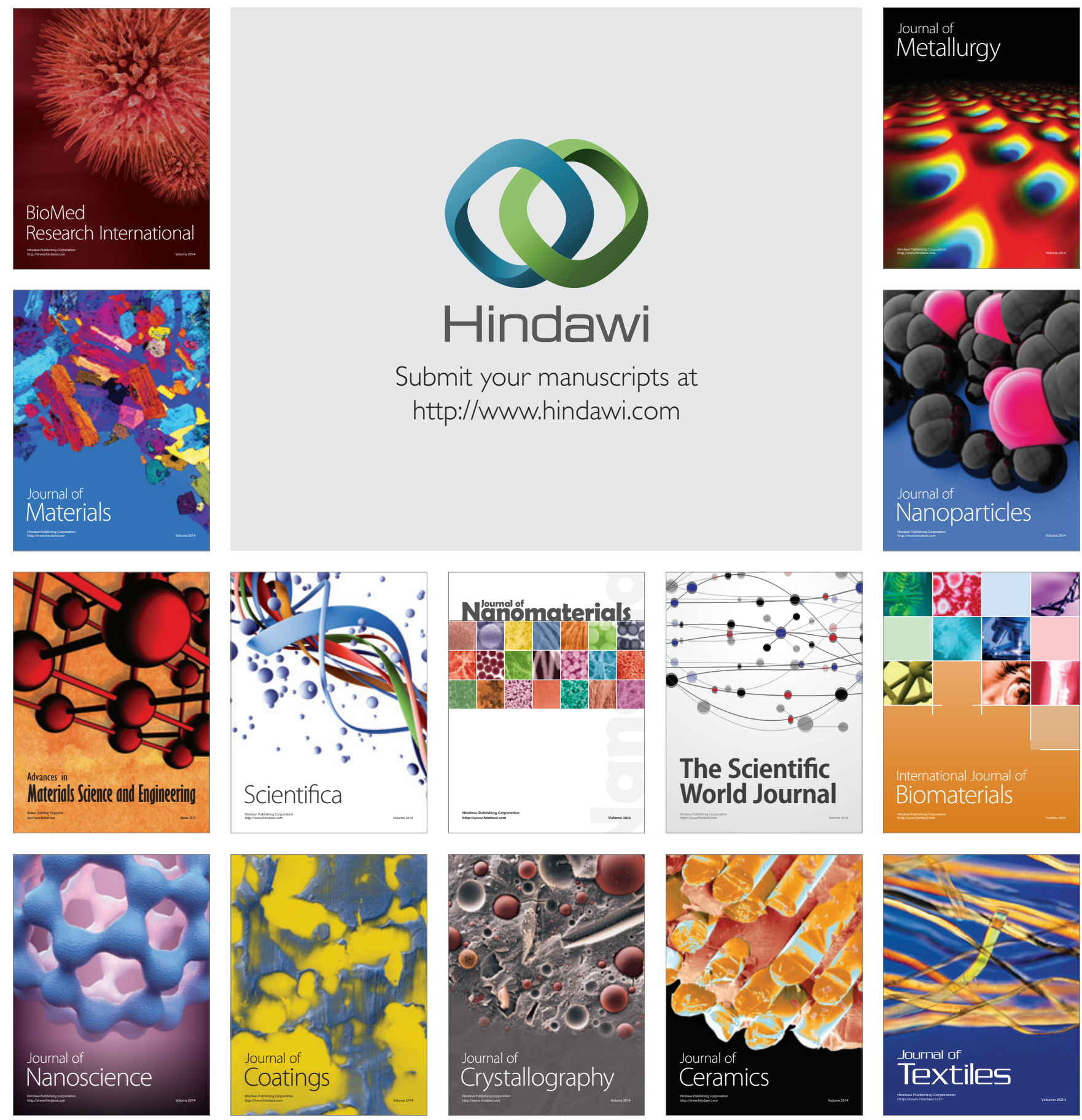